\title{
La autonomía e independencia: análisis de la efectividad del cuarto principio del cooperativismo bajo la perspectiva de la ontología cooperativa
}

(Autonomy and independence: analysis of the effectiveness of the fourth principle of cooperativism under the perspective of cooperative ontology)

\author{
José Eduardo de Miranda1 ${ }^{1}$ Andrea Corrêa Lima² \\ Centro Universitário Montes Belos (Brasil)
}

Sumario: Introducción. I. Del significado de principio hacia los principios cooperativos. II. Autonomía e independencia: el cuarto principio cooperativo. III. De la ontología a la ontología cooperativa. IV. A título de últimas reflexiones: la efectividad del principio de la autonomía e independencia desde una perspectiva de la ontología cooperativa. V. Referencias.

Summary: Introduction. I. From the meaning of principle towards cooperative principles. II. Autonomy and independence: the fourth cooperative principle. III. From the ontology to the cooperative ontology. IV. As a last thought: the effectiveness of the principle of autonomy and independence from a cooperative ontology perspective. V. References.

Resumen: La efectividad de los principios cooperativos está subrogada a la tenacidad de la aplicación conjunta de todos, de manera sistemática, y no de la observación de uno, o de algunos. Por esto, hay que entenderse que el principio de la autonomía e independencia no se muestra como una pauta individual, y su esmero condiciona la efectividad de otros principios, como el de la gestión democrática. En este sentido, la conformación de conjunto de principios traduce, desde la perspectiva ontológica del Cooperativismo, la condición del ser cooperativo en potencia, que es la sociedad cooperativa que alcanza, además de su proyección económica, el cumplimento del espíritu cooperativo.

Palabras clave: Autonomía e independencia, Efectividad, Ontología cooperativa.

1 Doctor en Derecho. Rector de la UniMB/Brasil, Abogado, consultor y conferencista. Correo electrónico: jemiranda@mirandacorrealima.com

2 Mestra en Derecho. Supervisora Académica de la UniMB, Abogada. Correo electrónico: andrea@mirandacorrealima.com 
Abstract: The effectiveness of the cooperative principles is subrogated to the tenacity of the joint application of all, in a systematic way, and not of the observation of one, or of some. Therefore, it must be understood that the principle of autonomy and independence is not shown as an individual guideline, and its dedication conditions the effectiveness of other principles, such as that of democratic management. In this sense, the conformation of a set of principles translates, from the ontological perspective of Cooperativism, the condition of the potential cooperative being, which is the cooperative society that achieves, in addition to its economic projection, the fulfillment of the cooperative spirit.

Keywords. Autonomy and independence, Effectiveness, Cooperative Ontology. 
A angústia revela ao ser o poder-ser mais próprio, ou seja, o serlivre para a liberdade de assumir e escolher a si mesmo. A angústia arrasta a presença para o ser-livre para... (propensio in...), para a propriedade de seu ser enquanto possibilidade de ser aquilo que já sempre é. A presença como ser-no-mundo entrega-se, ao mesmo tempo, à responsabilidade desse ser.

(Martin Heidegger, 1988, p. 252)

\section{Introducción}

Hoy por hoy, cuando el siglo XXI camina de manera acelerada en la dirección de su vejez, no hay más dudas teóricas sobre la importancia de Cooperativismo en el proceso de desarrollo de la humanidad, especialmente a partir de la Revolución Industrial, cuando el mundo conoció la Sociedad de los Probos Pioneros de Rochdale, tipificada como el punto de partida del Cooperativismo moderno.

En este sentido, que el Cooperativismo conforma sus características universales, pasando a ser reconocido como «un movimiento de aproximación de gentes que se han unificado bajo valores y principios comunes para eliminar problemas de distintos órdenes, derogar las formas autoritarias de poder fundado en la fuerza o la violencia del mandatario, y hasta para suprimir el poder autocrático del patrón» (Angueira Miranda, 1975, p. 15).

Desde entonces, el Cooperativismo fortaleciese como un fenómeno indicativo de la cooperación, y personifica una propulsión que tiene origen en las muchedumbres solidarias preocupadas unas con las condiciones de vida de las otras. Es así que la Alianza Cooperativa Internacional sistematizó la unificación de los principios cooperativos, lo que hizo con el propósito de resguardar la ideología inherente a la acción cooperativa.

Por ello, a lo largo de los múltiples Congresos editados por la $\mathrm{ACl}$, los principios cooperativos son tratados por los cooperativistas como herramientas que sostienen las sociedades cooperativas como estructuras organizadas para la complacencia de escaseces variadas, "una estructura que se desenvuelve a partir de la puesta en práctica de valores que permiten el desarrollo de la acción humana dirigida a la búsqueda de un bien que es común para todo un sector fragilizado: el bienestar del hombre, el bien social, económico y sobre todo, espiritual, puesto que el hombre cooperativo solo está bien, cuando sus semejantes también lo están» (Miranda, 2012, p. 30). 
Para garantizar la primacía de los principios cooperativos, de manera que su contenido contextual fuese utilizado como un programa completo característico de los principios teóricos y de las reglas prácticas de organización y funcionamiento de las sociedades cooperativas, la Alianza Cooperativa Internacional utilizó el Congreso de Manchester, en el año de 1995, para integrar el elenco de los principios vectores de la cooperación en el seno de la Declaración sobre la Identidad Cooperativa, estableciendo que son el los principios cooperativos que se deben basar las sociedades cooperativas (Miranda, 2012).

En el Congreso de celebración de su centenario, la $\mathrm{ACl}$, mientras define que los principios del Cooperativismo «ganan un perfil paradigmático, puesto que a la vez representan un modelo de pautas para evaluar el comportamiento y para tomar decisiones» (Miranda, 2016, p. 124), puntualiza que los principios de la cooperación son la adhesión abierta y voluntaria, la gestión democrática por parte de los socios, la participación económica de los socios, la autonomía e independencia, la educación, formación e información, la cooperación entre cooperativas y el compromiso con la comunidad.

A par de ello, el presente trabajo tiene el objetivo de analizar la efectividad del cuarto principio del Cooperativismo. Buscase, a través de una revisión literaria, suscitar el examen ontológico de la cooperación, imprescindible para la comprensión de la causa-efecto de la autonomía e independencia cooperativa. El estudio, singular, tendrá como sustentáculo la orientación preliminar de Aristóteles sobre el sentido de ontología, y, así mismo, sobre el significado del ser en cuanto acto y en cuanto potencia.

\section{Del significado de principio hacia los principios cooperativos}

De un modo muy peculiar, los principios cooperativos constituyen patrones que orientan el ejercicio de la cooperatividad, delimitando la naturaleza personal, democrática y solidaria de las sociedades cooperativas y de sus miembros. (Miranda, 2017)

Es en el sentido de esta máxima, que la expresión principio trata de «um padrão que deve ser observado, não porque vá promover ou assegurar uma situação econômica, política ou social considerada desejável, mas porque é uma exigência de justiça ou equidade ou alguma outra dimensão de moralidade». (Dworkin, 2002, 36)

Teniendo en cuenta el origen de la palabra, principio corresponde a los «mandatos de optimización porque ordenan que algo se realice en la mayor medida posible, de acuerdo con las posibilidades fácticas o ju- 
rídicas. Este mandato tiene en realidad un carácter definitivo» (Alexy, 2003, 55).

Son, pues, los principios, mandatos que se optimiza, o, a bien de la verdad, mandatos a optimizar. Contienen, en línea general, un deber ser ideal, que empresta pureza al sentido de que los principios son, a priori, mandatos efectivamente de optimización.

En el mundo de la vida, en que las personas y las instituciones celebran relaciones recíprocas, los principios son adoptados como pautas fundamentales que constituyen las auténticas pilastras de sustentación de regímenes sociales, económicos, políticos, jurídicos y cooperativos. Como tal, y en el orden cooperativo, es posible decir que en:

[...] el centro de las cooperativas, no son independientes el uno del otro. Están unidos sutilmente; cuando se pasa uno por alto, todos se resisten. No hay que evaluar las cooperativas exclusivamente en base a un principio dado; más bien, deben ser evaluadas en función de cómo se adhieren a los principios en su totalidad. (Alianza Cooperativa Internacional, 1996, p. 45)

Por esto, no se puede fragilizar la convicción de que es a través de los principios cooperativos que los cooperativistas abrigan las ideas generales que «inspiran y gobiernan la aplicación de la técnica cooperativa de organización social. Estas ideas resultan del razonamiento inductivo sobre la experiencia de realidades sociales universales» (Watkins, 1989, p. 31-32).

A partir de esta perspectiva, queda muy notorio que:

En el vasto mundo del Cooperativismo, los principios son comunes a los diversos tipos de clases de cooperativas y formas de cooperación en todo tiempo y lugar. La prueba de legitimidad de las entidades cooperativas, así como la garantía de una práctica, eficiente, y sólida consolidación, se hace con el examen de la presencia no de uno, pero sí de todos los principios. (Miranda, 2016, p. 125)

Así es que los principios cooperativos resultan considerados como «verdades universales para la formación y el ensanchamiento de un orden social donde la sociedad libre anhele vivir pacífica y prospera en colaboración. Resisten la ordenación constringente, hacen superfluo todo conflicto destructivo y descentralizan la fiscalización social y económica» (Miranda, 2016, 86).

A partir de allí, la $\mathrm{ACl}$ esclarece que:

Mucha gente entiende los principios como mandamientos firmes que deben ser seguidos literalmente. En un sentido es verdad, en la 
medida que deberían proporcionar normas de conducta. En otro sentido, deberían restringir, incluso prohibir, ciertas acciones mientras estimulan otras.

Sin embargo, los principios son más que mandamientos, son pautas para evaluar el comportamiento y tomar decisiones. No es suficiente preguntar si una cooperativa está siguiendo al pie de la letra un principio dado; es igualmente importante saber si está siguiendo el espíritu —si la visión que proporciona cada principio, individual y colectivamente, está arraigada en las actividades diarias de la cooperativa-. En este sentido, los principios no son una lista caduca a revisar periódicamente y de forma ritual; son marcos de actuación capacitadores - agentes que dan energía - por los cuales las cooperativas pueden alcanzar el futuro. $(\mathrm{ACl}, 1996,88)$

Por tanto, es corriente el entendimiento de que los principios «constituyen el alma de las sociedades cooperativas, sirven para la puesta en práctica de los valores cooperativos, y no pueden ser observados de manera independiente uno del otro.»(Miranda, 2017) Además, se puede afirmar que en virtud de la aplicación práctica de los principios cooperativos que se tiene garantizada «la naturaleza democrática de las cooperativas, el papel de los diferentes partícipes y la forma de distribuir excedentes»(Gadea, Sacristán y Vasserot 2009, 38).

Los principios cooperativos determinan las cualidades esenciales que hacen que las cooperativas sean diferentes a los otros tipos de empresa y que el movimiento cooperativo sea valioso. Por tanto, su importancia dogmática es evidente, aunque su transcendencia jurídica queda supeditada a los términos en que hayan sido incorporados en las respectivas legislaciones internas, lo que condiciona notablemente su posible eficacia como criterios correctores de posibles impurezas del legislador correspondiente. Ello, no obstante, su carácter informador de la estructura y funcionamiento de la cooperativa, les adiciona un claro valor como elemento de interpretación de la normativa cooperativa. (Gadea, Sacristán y Vasserot, 2009, 38)

Por todo ello, es absolutamente viable certificar que «la $\mathrm{ACl}$ ha establecido que los principios dejan de representar un elenco de singularidad reglamentaria, y se revisten del aspecto representativo de un modelo de comportamiento y de la toma de decisiones» (Miranda, 2012, p. 51). 


\section{Autonomía e independencia: el cuarto principio cooperativo}

El cuarto principio cooperativo, delineado por la $\mathrm{ACl}$ en la Declaración sobre la Identidad Cooperativa, en el Congreso de Manchester, orienta que:

Las cooperativas son organizaciones autónomas de autoayuda, gestionadas por sus socios. Si firman acuerdos con otras organizaciones, incluidos los gobiernos, o si consiguen capital de fuentes externas, lo hacen en términos que aseguren el control democrático por parte de sus socios y mantengan su autonomía cooperativa. ( $\mathrm{ACl}$, 1996, 123)

El principio de la autonomía e independencia preconiza la condición absoluta de que las sociedades cooperativas sean constituidas y desarrollen sus actividades bajo la plena protección de cualquier intervención externa, que rompa la estabilidad y armonía decurrente del principio de la gestión democrática por parte de los socios. En este sentido, es importante tener en cuenta que la propia Alianza Cooperativa Internacional estableció que la democracia indica que:

Las cooperativas son organizaciones gestionadas democráticamente por los socios, los cuales participan activamente en la fijación de sus políticas y en la toma de decisiones. Los hombres y mujeres elegidos para representar y gestionar las cooperativas son responsables ante los socios. En las cooperativas de primer grado, los socios tienen iguales derechos de voto (un socio, un voto), y las cooperativas de otros grados están también organizadas de forma democrática. $(\mathrm{ACl}, 1996,115)$

La conexión precisa entre la autonomía e independencia, con el principio de gestión democrática, no es objeto de la casualidad. Una vez que la reformulación de los principios cooperativos, por la $\mathrm{ACl}$, y bien así, la enunciación de los valores del Cooperativos resultaron de minuciosos estudios realizados en el recorrido del tiempo, los expertos da la Alianza Cooperativa Internacional no despreciaron que la historia, por si misma, demostró que las cooperativas, en todas las partes del mundo, se han visto afectadas por sus relaciones con el Estado. Nadie jamás podrá omitir que:

[...] las políticas cooperativas aplicadas en muchos países no han promovido un impacto tangible, puesto que la mayoría de las iniciativas gubernamentales no han servido para promover adecuadamente 
las cooperativas y para poner en manifiesto su naturaleza y particularidades ideológicas. Solo ha servido para favorecer el desarrollo de un sinfín de actividades mediante falsas cooperativas, dado que en muchos casos carecían de autonomía e independencia, debido a la subordinación económica y política a los diversos organismos que otorgaban subvenciones o encargos de obras a las entidades constituidas mediante la ayuda estatal. Esta sumisión queda patente cuando observamos que en muchos países donde sus gobiernos han ofrecido la prestación de servicios especiales para la promoción y control de las cooperativas, las subvenciones aparentemente destinadas al desarrollo cooperativo han sido utilizadas para la promoción del propio organismo gubernamental que ha sido creado para el fomento cooperativo.

Con el paso de los años estos organismos se han transformado en burocracias con muchos funcionarios desprovistos de la adecuada formación sobre la materia que les han asignado la responsabilidad para el desarrollo y la protección. (Miranda, 2012, p. 40-41)

Münkner advierte que «presupuestos para gastos gubernamentales estancados o reducidos y una legislación cooperativa que le confiere al gobierno cada vez más atribuciones para supervisar y controlar a las cooperativas, el concepto de cooperación controlada por el Estado ha alcanzado sus límites de aplicabilidad. El control estatal se extiende y encarece cada vez más pero sigue siendo ineficiente en gran medida» (Münkner, 1992, p. 58)

Es importante recordar que una escalada de cambio social sin precedentes se ha producido en los países del este de Europa. Cambios equivalentes en las circunstancias sociales han afectado el entorno de las cooperativas en los países en desarrollo. Estos cambios han exigido que el movimiento cooperativo reevaluase su posición, principalmente con relación a su trato con el Estado, a la ubicación de la autonomía cooperativa y al reconocimiento de la cooperación como una parte integral, e independiente de la sociedad plural (Miranda, 2012, p. 280)

Hay que mantenerse el ojo atento al hecho de que la esencia de la gestión democrática «es el voto unipersonal y no el proporcional, lo que supone un «populismo» en el control de las sociedades cooperativas, que impide los bloqueos orgánicos por reducido número de partícipes» (Miranda, 2016, p. 127), o mismo la interferencia externa, sea en virtud de la intervención del Estado o mismo de entidades otra pasibles de relacionarse con la cooperativa.

Mac Pherson llama la atención al hecho de que «los gobiernos establecen el marco legislativo dentro del cual pueden funcionar las 
cooperativas. En sus políticas impositivas, económicas y sociales, los gobiernos pueden ser útiles o perjudiciales en su trato con las cooperativas. Por tal motivo todas las cooperativas deben estar alertas para desarrollar con los gobiernos relaciones abiertas y claras» (Mac Pherson, 1944, p. 28).

Además, es nítido que la «relación autonomía-democracia constituye el ideal que los precursores han establecido a lo largo de sus actuaciones, a favor de la constitución de asociaciones independientes, conducidas por sus miembros, en favor de ellos, libres de cualquier interferencia administrativa o ideológica venida del exterior de la entidad» (Miranda, 2012, p. 59).

De otra forma, el vínculo indiscutible entre los dos principios da respuesta a las exigencias de cimentar una economía basada en la fe, en los valores espirituales del hombre, una economía que coloque a los tecnócratas por debajo de la democracia; una economía, en fin, de responsabilidades y asociación.

Coligando el principio cuarto a la realidad de los Probos Pioneros de Rochdale, resuelta interesante decir que los Pioneros crearon una cooperativa "cuyo desarrollo se ha realizado bajo la más absoluta autonomía e independencia, que, a nuestro juicio, refleja un indiscutible grado de libertad relativa a los socios y a la propia sociedad» (Miranda, 2012, p. 59).

La historia registró, por lamentable, que «el excesivo proteccionismo de las entidades públicas, en relación a las cooperativas, puede provocar que las primeras busquen en éstas una vía de promoción, apoyo o búsqueda de sus propios objetivos» (Miranda, 2016, p. 129).

Por supuesto, e en virtud de ello, toda fuente financiera que provenga de acreedores ha de ser remunerada de acuerdo con lo pactado, «sin que ello suponga más dependencia de la que conlleva a la retribución pactada o negociada a otros factores que contribuyen a la creación de valor en lo que de empresarial tiene la sociedad cooperativa» (García-Gutiérrez Fernández, 1995, p. 66). Es así que:

La introducción de esas figuras financiadoras participativas que algunos tratadistas, sobre todo franceses, han propuesto, y que tan poco éxito han tenido, y que algunas normativas económicas han incorporado son ajenas al significado intrínseco de lo que es la sociedad cooperativa, en la que las decisiones sólo están basadas en la participación en el objeto social de la empresa que acometen empresarialmente los socios. (García-Gutiérrez Fernández, 1995, p. 66)

Observándose la relación socio-cooperativa, no se debe ocultar que «los primeros, ejercen esta libertad a la luz del vínculo que hemos es- 
tablecido entre autonomía-democracia. La entidad, a su vez, como organización autónoma e independiente, logra garantizar la eficacia económica de su actividad» (Miranda, 2012, p. 59). Asimismo, «cuando la libertad de la cooperación está protegida y balanceada, como lo estaba en Rochdale, no puede degenerar en ninguna forma de desorden, anarquía» (William Mercer, 1995, p. 16), o interferencia externa.

\section{De la ontología hacia la ontología cooperativa}

Correlacionar el termino ontología con el sentido de la cooperatividad, comprende un ejercicio filosófico indispensable para la comprensión epistemológica del Cooperativismo y de la sociedad cooperativa.

Esto, es cierto, revelase fundamental para los primeros pasos hacia la cientificación de la materia cooperativa, y para el alcance da la autonomía del propio Derecho Cooperativo. Por tanto, y mismo sin un análisis profundo en el universo de los filósofos que se encargaran de investigar la ontología, aquí, para cumplir el objeto del presente trabajo, el camino empieza en la necesidad de entenderse o que es la ontología.

Observada desde una ubicación filosófica, ontología, derivada de las palabras griegas ontos y logos, ser y saber, respectivamente, es la rama de la filosofía responsable del estudio del "conhecimento do Ser, dos entes ou das coisas tais como são em si mesmas, real e verdadeiramente, correspondendo ao que Aristóteles chamara de Filosofia Primeira, isto é, o estudo do Ser enquanto Ser» (Chauí, 2012, p. 229). Es de este modo, que se confirma, entonces, que la palabra ontología:

[...] é composta de duas outras: onto e logia. Onto deriva de dois substantivos gregos, tà onta ( os bens e as coisas realmente possuídas por alguém»; e "as coisas realmente existentes»). Tà onta deriva do verbo ser, que, em grego, se diz einai. O particípio presente desse verbo se diz on (sendo, ente). Dessa maneira, as palavras tà onta («as coisas») e on («ente») levaram a um substantivo: tò on, que significa "o Ser». O Ser é o que é realmente e se opõe ao que parece ser, à aparência. (Chauí, 2012, p. 229)

De acuerdo con Castro, el término ontología es el «resultado da junção de dois termos gregos onta (entes) e logos (teoria, discurso, palavra). Ao pé da letra, ontologia significa, portanto, teoria dos entes. «Ente» está aí representando todas as coisas sobre as quais se pode dizer que são - ou que a ontologia é a teoria do ser enquanto tal» (Castro, 2008, p. 7). 
Originariamente, la ontología tiene origen en la obra de Aristóteles, Metafísica, conocida como la «Primera Filosofía», que utilizó para tratar del estudio del ser, en su esencia (Aristóteles, 2002). Buscando justificar el sentido de su obra, Aristóteles fue enfático cuando dijo que:

[...] Existe uma ciência que considera o ser enquanto ser e as propriedades que the competem enquanto tal. Ela não se identifica com nenhuma das ciências particulares: de fato, nenhuma das outras ciências considera universalmente o ser enquanto ser, mas, delimitando uma parte dele, cada uma estuda as características dessa parte. Assim fazem, por exemplo, as matemáticas.

Ora, dado que buscamos as causas e os princípios supremos, é evidente que estes devem ser causas e princípios de uma realidade que é por sí. Se também os que buscavam os elementos dos seres, buscavam esses princípios "supremos», necessariaemnte aqueles elementos não eram elementos do ser acidental, mas do ser enquanto ser. Portanto, também nós devemos buscar as causas do ser enquanto ser. (Aristóteles, 2002, 132)

En la ruta de su construcción, Aristóteles es predestinado en su trabajo de identificación de la esencia del ser, esclareciendo que en la búsqueda por la esencia hay que buscarse los principios y las causas de la propia esencia. Por esto, el filósofo griego sugiere que si el todo existe como un cierto todo, la esencia siempre va a ser la parte principal, y de esta manera será mismo que si el todo existe en secuencia, la esencia estará en primero. "La esencia de cada cosa es todo lo que ella es por sí misma» (Aristóteles, 2002, p. 297).

Es así que, desde una perspectiva aristotélica, no hay como rechazarse que la ontología se ocupa de la descripción de las estructuras de un ser, restringiéndose en el entendimiento del fenómeno que el ser en sí mismo dejar ver. Para ilustrar su creación, Aristóteles señala, como ejemplo, que la esencia del hombre y la del no-hombre significan cosas diferentes. (Aristóteles, 2002). La esencia del ser solamente se muestra posible comprender cuando el ser es determinado.

Para mantener el hilo con la propuesta de este trabajo, es importante decir que, de los varios sentidos que ofrece en su Metafísica, Aristóteles subraya que el ser, o el ente, significa el ser en potencia, o en el acto. Acto y potencia, en el discurso de Aristóteles, se muestran como modos de ser divergentes, distintos.

Cuando expresa que hay un ser en acto, Aristóteles es convicto de que el ser existe de manera concreta, resguardando su existencia real, para cumplir la tenacidad de su razón existencial. De otra forma, en el 
momento que suscita la existencia del ser en potencia, el filósofo manifiesta que dicho ser tiene la facultad de realizar su existencia, lo que justifique su condición existencial, mismo que de modo desnecesario.

Mirándose la condición del ser, en acto y potencia, Aristóteles deja claro que el ser puede existir: i) en cuanto acto, pero no en potencia; ii) en cuanto acto y potencia; iii) en cuanto potencia, pero no en acto.

Esta multiplicidad de posibilidades, en la forma de ser, genera algunas implicaciones, como: i) mientras exista en acto, pero no exista en potencia, hay una existencia necesaria de ser, de manera que ello no puede ser diferente do que tiene que ser; ii) en cuanto exista en acto y potencia, el ser existe, pudiendo transformarse en otra cosa en relación a lo que es, o debería ser; iii) si existe en potencia, pero no existe en acto, el ser existe en posibilidad, pero su existencia no es necesaria o efectiva (Aristóteles, 2002).

Es así que se quiere llegar a la ontología cooperativa, partiendo del supuesto de que en materia cooperativa, la ontología describe las estructuras del ser sociedad cooperativa, con relieve exclusivo al que el fenómeno cooperativo determina.

Por este camino, la ontología cooperativa debe tener en cuenta el raíz de entendimiento de la sociedad cooperativa, por lo cual se tiene que estas con verdaderas «formas de defensa y reacción de amplios sectores de la población mundial que, frente a la insatisfacción de una diversidad de necesidades socioeconómicas, y conscientes de su debilidad individual, han decidido articular sus esfuerzos y fortalecerse a través de la ayuda mutua y la acción común» (Miranda, 2012, 26).

Bajo esta proyección, no se puede alejar este estudio del significado de sociedad cooperativa prescrito en Declaración de la Identidad Cooperativa, entendiéndose que las sociedades cooperativas son asociaciones de personas que se unen de forma voluntaria para satisfacer sus necesidades y aspiraciones económicas, sociales y culturales en común, por medio de una empresa de propiedad conjunta y gestión democrática. Es así que la $\mathrm{ACl}$ establece que:

Las cooperativas también abarcan metas culturales en armonía con las preocupaciones de los socios: por ejemplo, ayudar en la promoción de la cultura nacional, promover la paz, patrocinar deportes y actividades culturales, y mejorar las relaciones en la comunidad. De hecho, ayudar a proporcionar una mejor forma de vida — cultural, intelectual y espiritual- podría en el futuro convertirse en una de las formas más importantes en las que las cooperativas pueden beneficiar a sus socios y hacer una contribución a sus comunidades. (ACl, 1996, 93) 
Es a partir de esta idea que se puede empezar la formulación de una ontología cooperativa cuando se entienda definitivamente que, mientras la sociedad cooperativa tiene como finalidad la promoción del bien general de sus miembros, pues su ejercicio transciende la satisfacción de necesidades económicas, no se puede soterrar que la sociedad cooperativa también tiene el fin de remediar problemas de orden moral y social de los propios asociados, desarrollando, además, una colaboración con la solución de problemas generales de las gentes de la comunidad.

En este sentido, y pensándose en la ontología cooperativa, es esencial no despreciar que el Cooperativismo es «un sistema ordenador de la vida social, no sólo una forma de empresa» (Miranda, 2012, p. 15). Imposible, por tanto, desecharse que:

El Cooperativismo recorrió la historia de manos dadas con el hombre como una corriente que permitió que las gentes se aproximaran bajo valores y principios comunes, para eliminar todas las formas autoritarias de poder, y para permitir que el propio hombre encontrara los medios necesarios a su completo desarrollo en el ámbito material, económico, social, personal y espiritual. (Miranda, 2012, p. 15)

La ontología cooperativa, pues, entiende la sociedad cooperativa, y el propio Cooperativismo, desde su matiz axio-principiológico, resguardando que la causa de uno y de otro es la preservación del espíritu de la cooperatividad, representativo de la salvaguardia de intereses superiores al alcance de una expectativa meramente económica, o material: la preocupación de las cooperativas es con el bien común, con el bien de todos, sean, o no, cooperados.

Esta característica, no se puede rechazar, está presente en el núcleo central de la Declaración sobre la Identidad Cooperativa, emitida por la Alianza Cooperativa Internacional en el año de 1995, en Manchester. Tanto es así, que desde una expectativa de conferirse protección al sentido de la identidad cooperativo, no es exagero decir que:

La Declaración de esta identidad, no ha significado una vuelta atrás, en el sentido de la primitivización del movimiento, o de la entidad a él adherida. El hecho identificador comprende el desvelo de lo más importante que el Cooperativismo ha tenido, desde que ha surgido en Toad Lane: sus valores. Unos valores representativos de la esencia del movimiento, desde sus comienzos. Unos valores particulares, también de los individuos colaboradores. Unos valores que pueden despegarse de las fronteras internas de la entidad coopera- 
tiva para irradiar en distintos entornos una eficaz alternativa de rescate de lo que parece perdido, y de fortalecimiento de lo que se encuentra débil. (Miranda, 2012, p. 30)

\section{A título de últimas reflexiones: la efectividad del principio de la autonomía e independencia desde una perspectiva de la ontología cooperativa}

Mirándose hacia la causa y el efecto del principio de la autonomía y de la independencia, es necesario resguardarse su absoluta relación con el principio de la gestión democrática, de forma tal que se defienda que una cooperativa siempre va a ser una cooperativa cuando mantenga evidente la esencia del espíritu cooperativo.

El ser autónomo e independiente, es, como así dijo Aristóteles, el ser en acto y potencia. La sociedad cooperativa va a ser sociedad cooperativa en su magnitud, cuando su existencia cumpla la finalidad transcendental de su creación, la cual suplanta un objetivo meramente económico.

No se puede, jamás, olvidar que «a lo largo de los años ochenta, una serie de cambios han afectado a la forma de acción de las cooperativas, provocando un profundo abatimiento en su ámbito ideológico, hasta el punto de dejarlas bajo una difícil crisis de identidad, que ha afectado a su estructura, determinando la pérdida de su credibilidad» (Miranda, 2012, p. 30).

La historia deja evidente que la falta de preparación de sus administradores, gerentes, y de los asociados en general (éstos, en la gran mayoría de los casos, erran por omisión, ya que ni siquiera asisten a las asambleas generales), ha sido la principal responsable de la elevada «mortalidad cooperativa», tal como ocurre con las pequeñas y medias empresas económicas, en el marco de la sociedad cooperativa» (Benevides Pinho, 1987, p. 137).

En razón de ello, es primordial que el ejercicio existencial de la cooperativa preserve entre los cooperados el sentimiento de que «la cooperación siempre ha sido un instrumento para superar las individualidades, que la cooperativa es la unión de esfuerzos y voluntades, y que el Cooperativismo es una emancipación del espíritu humano que lleva en sí una fuerza que le viene de su contenido dinámico; adopta el principio de servicio y descansa en la ayuda mutua» (Miranda, 2012, p. 48).

Por supuesto, la autonomía e independencia, en cuanto principio vector del ejercicio de la sociedad cooperativa, llevará las cooperativas 
a la efectividad de un resultado económico perene, siempre y cuando la gestión democrática no sufra la influencia de elementos externos que puedan corromper el sustrato ideológico del Cooperativismo, contaminando la esencia de la entidad, de manera que se transforme únicamente en un ser en acto, perdiendo la sustancia de ser en potencial.

Acredítase, con eso, que:

[...] das características herdadas geneticamente e tendo em vista a necessidade de estarem vinculadas a um grupo social, as pessoas unem-se em projetos com objetivos comuns, sem visar lucros. Essa união, além da quebra do individualismo humano, visa liberar o homem da ignorância, por meio de um poderoso instrumento denominado cooperação. Em virtude dessa identidade, os indivíduos associados entre si buscam a satisfação de suas necessidades, da defesa e da reforma pacífica e gradual da coletividade, bem como da solução de problemas comuns, por intermédio da união, auxílio mútuo e integração entre pessoas. Assim, busca-se a correção dos grandes desníveis e injustiças sociais, bem como a repartição eqüitativa e harmoniosa de bens e valores. Dessas particularidades em comun existentes entre as pessoas é que surge aquilo que mundialmente chamamos de identidade cooperativa. (Teixeira Júnior, 2001, p. 398)

La autonomía e independencia, y, por conexión, la democracia, pierde su efectividad, afligiendo inclusive la identidad de la sociedad cooperativa, con distorsión del espíritu del Cooperativismo, en situaciones de:

[...] conflictos entre exigencias de carácter económico y de carácter social, entre planteamientos puramente empresariales y los intereses económicos de los socios; reacción lenta a los cambios, debido al carácter democrático y participativo de los órganos de decisión; dificultad para hacer prevalecer la autoridad y mantener la disciplina, cuando los directores y mandos intermedios son elegidos por sus propios compañeros de trabajo, directa o indirectamente; riesgo de autoexploración de los recursos humanos, sobre todo cuando la coyuntura es recesiva, soportando condiciones más desfavorables (número de horas de trabajo, salarios, etc.) que los trabajadores por cuenta ajena. (Vargas Sánchez, 1995, p. 188)

Todavía se hace presente en el universo del Cooperativismo, la historia de los fracasos de muchas cooperativas, lo que es utilizado como argumento demasiadamente esgrimido contra las cooperativas.

Por esto que el movimiento cooperativo debe «asumir, sin embargo, la crítica de la ausencia de auténticos cooperativistas como ori- 
gen de muchos fracasos, entendiendo por tal aquel que asume una ideología, cree en unos valores y trata de llevarlos a la práctica; y es que ser cooperativista es algo más que saber sobre cooperativismo o ser socio de una cooperativa» (Vargas Sánchez, 1995, p. 186).

La pérdida de la autonomía y de la independencia lleva las cooperativas fracasaren no apenas como empresa. Esta ruptura, que afecta la propia democracia cooperativa, provoca también el rompimiento de proyección social, humana y espiritual del Cooperativismo. Es así que se muestra importante no olvidarse, nunca jamás, que: El siempre presente profesor Aranzadi, enseñó que:

[...] muchas cooperativas han nacido con grandes ideales y con gran entusiasmo de los cooperativistas para realizarlos. Resulta penoso constatar que todos esos ideales vengan abajo y los hombres queden hundidos porque no han tomado en consideración una de las dos columnas sobre las que se sostiene el edificio cooperativo. Es como si llenásemos un bidón más, y resultara que el coche no andaba porque le faltaban las ruedas o porque no funcionaba el motor, que son condiciones para que el coche ande». (Aranzadi, 1992, p. 292)

Dicho esto, el inolvidable profesor esclarece que «si las desgracias de unos hombres no fuesen suficientes, arrastrará también "como secuela, el descrédito de la institución"»(Aranzadi, 1992, p. 292).

Hay, con ello, un efecto generalizado que suplanta la individualidad existencial de la sociedad cooperativa, afectando de manera directa el sistema cooperativo como como un todo, disminuyendo la fortaleza de sus ideales, el sentido de sus valores y el significado de sus principios. Además:

Hay, por tanto, que sobrellevarse la conciencia del universo cooperativo que las extravagancias inherentes a las distintas ramas del Cooperativismo son predisposiciones malas que el día menos pensado someterán los cooperativistas a una nueva crisis de identidad que, quizás, le afecte de tal manera su estructura y funcionalidad que pierda definitivamente su razón de ser, su marca de representatividad como la alternativa que, más allá de permitir el desarrollo socioeconómico del hombre, le permite una evolución moral y mismo espiritual. (Miranda, 2016, p. 156)

En vista de ello, «no sólo fracasa una cooperativa, sino que en el entorno al menos queda herido el cooperativismo» (Aranzadi, 1992, p. 292). Es así que el ser cooperativo esencialmente en acto fallecerá, llevando con él la perseverancia identitaria de todo el Cooperativismo. 


\section{Referencias}

ALEXY, Robert. 2003. "Tres escritos sobre los derechos fundamentales y la teoría de los principios». N 28. Serie de teoría jurídica y filosofía del Derecho. Universidad de Externado de Colombia: Bogotá.

ALIANZA COOPERATIVA INTERNACIONAL. 1996. "Declaración de la Alianza Cooperativa Internacional sobre la Identidad Cooperativa aprobada en Manchester.» Anuario de Estudios Cooperativo. Bilbao: Universidad de Deusto.

ANGUEIRA MIRANDA, M.A. 1975. Hacia la comunidad cooperativa libre. 2. ${ }^{a}$ edición, Buenos Aires: Intercoop Editora Cooperativa Limitada.

ARANZADI, D. 1992. El arte de ser empresario hoy: hombres y mujeres ante el reto de dirigir empresas cooperativas en el umbral del siglo XXI. Bilbao: Departamento de Trabajo y Seguridad Social del Gobierno Vasco-Federación de las Cooperativas de Trabajo Asociado de Euskadi-Universidad de Deusto.

ARISTÓTELES. 1994. Categorias de Aristóteles. Tradução de Silvestre Pinheiro Ferreira. 3. ${ }^{a}$ ed. Lisboa: Guimarães Editores.

ARISTOTELES. 2002. Metafísica. São Paulo: Edições Loyola.

ARNÁEZ, Vega M. ${ }^{\text {a }}$ 2018. "La alternativa cooperativa en la prestación de servicios públicos sostenibles». Boletín de la Asociación Internacional de Derecho Cooperativo 52: 123-135. doi: http://dx.doi.org/10.18543/baidc-522018pp123-135

BENEVIDES PINHO, D. 1987. Evolución del pensamiento cooperativista. Buenos Aires: Intercoop Editora Cooperativa Limitada.

BRETOS, Ignacio; DÍAZ-FONCEA, Millán; MARCUELLO, Chaime y MARCUELLO, Carmen. 2018. "Cooperativas, capital social y emprendimiento: Una perspectiva teórica». REVESCO. Revista de Estudios Cooperativos, 128: 76-98. doi: http://dx.doi.org/10.5209/REVE.59775

CASTRO, S. 2012. Ontologia. Rio de Janeiro: Jorge Zahar.

CHAUÍ, M. 2012. Convite à Filosofia. 14. ${ }^{\text {a }}$ ed. São Paulo: Ática.

CHAVES, Rafael y MONZÓN, José Luis. 2018. «La economía social ante los paradigmas económicos emergentes: innovación social, economía colaborativa, economía circular, responsabilidad social empresarial, economía del bien común, empresa social y economía solidaria», CIRIEC-ESpaña, Revista de Economía Pública, Social y Cooperativa, 93: 5-50. doi: 10.7203/CIRIEC-E.93.12901.

DWORKIN, Ronald. 2002. Levando os Direitos a sério. Tradução de Nelson Boeira. São Paulo: Martins Fontes.

GADEA, Enrique; SACRISTÁN, Fernando y VARGAS, Carlos. 2009. Régimen jurídico de la sociedad cooperativa del siglo XXI. Realidad actual y propuestas de reforma. Madrid: Dykinson, S.L.

GAMINDE, Eba y MARTíNEZ, Gonzalo. 2019. «La formación en los valores cooperativos como elemento decisivo para los nuevos trabajos que crean las cooperativas del siglo XXI». Boletín de la Asociación Internacional de Derecho Cooperativo, 54: 97-114. doi: http://dx.doi.org/10.18543/baidc54-2019pp97-114 
GARCÍA-GUTIÉRREZ FERNÁNDEZ, C. 1995. «Las sociedades cooperativas de derecho y las de hecho con arreglo a los valores y a los principios del Congreso de la Alianza Cooperativa Internacional de Manchester en 1995. Especial referencia a las sociedades de responsabilidad limitada reguladas en España». Revista de Estudios Cooperativos.

HEIDEGGER, M. 1988. Ser e tempo (v. I). Petrópolis, RJ: Vozes.

LARRAZABAL, Santiago. 2019. "La sinergia entre las políticas de empleo y las cooperativas respecto a las nuevas formas de trabajo. Una perspectiva desde el Derecho Constitucional español». Boletín de la Asociación Internacional de Derecho Cooperativo, 54: 55-73. doi: http://dx.doi. org/10.18543/baidc-54-2019pp55-73.

MAC PHERSON, I. 1994. "La identidad cooperativa en el siglo veintiuno. Un documento de referencia». Revista de la Cooperación Internacional. 27, 3, $\mathrm{ACl}$.

MIRANDA, José Eduardo de. 2012. De la crisis de identidad al rescate de la génesis del Cooperativismo. Madrid: Dykinson.

MIRANDA, José Eduardo de. 2016. Filosofía cooperativa: análisis del proceso de conformación del Cooperativismo. Lisboa: Juruá.

MIRANDA, José Eduardo de. 2017. "De la adhesión voluntaria a las puertas abiertas a medias: la arbitrariedad en el incumplimiento de un principio cooperativo». Boletín de la Asociación Internacional de Derecho Cooperativo 51: 63-77. doi: http://dx.doi.org/10.18543/baidc-51-2017pp63-77

MORENO, Juan Luis. 2017. "Las relaciones entre los valores y principios cooperativos y los principios de la normativa cooperativa». REVESCO. Revista de Estudios Cooperativos, 124: 114-127. doi: http://dx.doi.org/10.5209/ REVE.54923.

MÜNKNER, H.H. 1992. "Los valores cooperativos y la ayuda para el desarrollo». Revista de la Cooperación Internacional. 25,2, ACl.

SOUZA, Leonardo Rafael de. 2018. "A devolução dos excedentes pelas cooperativas de crédito brasileiras: fomento à economia individual do associado em detrimento da sua efetiva participação econômica». Boletín de la Asociación Internacional de Derecho Cooperativo, 53: 139-155. doi: http:// dx.doi.org/10.18543/baidc-53-2018pp139-155.

TEIXEIRA JÚNIOR, A.B. 2001. "A identidade cooperativa e os princípios cooperativos no Brasil». Anuario de Estudios Cooperativos. Universidad de Deusto: Bilbao.

VARGAS SÁNCHEZ, A. 1995. "La identidad cooperativa y la cooperativa como empresa: luces y sombras». Revista de Estudios Cooperativos. 61.

WATKINS, W.P. 1989. Los principios cooperativos hoy y mañana. Bogotá: Esacoop.

WILLIAM MERCER, T. 1995. "Bases de la cooperación. Principios y métodos de Rochdale». Revista de la Cooperación Internacional. 28,2, ACl. 


\section{Derechos de autor}

El Boletín de la Asociación Internacional de Derecho Cooperativo es una revista de acceso abierto lo que significa que es de libre acceso en su integridad inmediatamente después de la publicación de cada número. Se permite su lectura, la búsqueda, descarga, distribución y reutilización legal en cualquier tipo de soporte sólo para fines no comerciales y según lo previsto por la ley; sin la previa autorización de la Editorial (Universidad de Deusto) o el autor, siempre que la obra original sea debidamente citada (número, año, páginas y DOI si procede) y cualquier cambio en el original esté claramente indicado.

\section{Copyright}

The International Association of Cooperative Law Journal is an Open Access journal which means that it is free for full and immediate access, reading, search, download, distribution, and lawful reuse in any medium only for non-commercial purposes, without prior permission from the Publisher or the author; provided the original work is properly cited and any changes to the original are clearly indicated. 